Tetrahedron Letters

journal homepage: www.elsevier.com

\title{
Iron-Catalyzed Allylic Substitution Reactions of Allylic Ethers with Grignard Reagents
}

\author{
Longying Qi, Enlu Ma, Fan Jia, and Zhiping Li* \\ Department of Chemistry, Renmin University of China, Beijing 100872, China
}

\section{ARTICLE INFO}

Article history:

Received

Received in revised form

Accepted

Available online

Keywords:

Iron catalysis

Allylic substitution

Allylic ether

Grignard reagent

Allyl iron

Transition metal-catalyzed allylic substitution reactions have evolved as versatile and powerful tools for organic synthesis. ${ }^{1}$ Active allylic substrates bearing halides, acetates, carbonates, etc. as leaving groups are commonly used in allylic substitution reactions. The development of allylic substrates involving readily available and nontoxic unactivated allylic substrates such as allylic alcohols and ethers has received significant attentions. ${ }^{2}$ The reported reactions of allylic alcohols mainly focused on their allylation with soft nucleophiles. Because of their stabilities to organometallic reagents, allylic ethers show great potential synthetic utilities in the reactions with hard nucleophiles. The excellent achievements are realized by copper, ${ }^{3}$ nickle, ${ }^{4}$ palladium, ${ }^{5}$ and other metals. ${ }^{6}$ The applications of inexpensive, easily available and nontoxic iron catalysts are promising alternative and thus attracting much attention in modern chemistry. ${ }^{7}$ In the past years, great progress has been made in the development of iron-catalyzed allylic substitutions, while the reactions are mainly conducted with soft nucleophiles. ${ }^{8}$ To our surprise, iron-catalyzed allylic substitution reactions between allylic substrates and organometallic reagents are rare. ${ }^{9}$ In 1994, Yamamoto $^{10}$ and coworkers reported an iron-catalyzed substitution reaction of allylic phosphates with Grignard reagents, resulting in $\alpha$-selective products (eq 1). Nakamura group $^{11}$ and Urabe group ${ }^{12}$ reported ring opening reactions of allylic epoxide substrates with Grignard reagents to achieve high regio- and stereo-selective products (eqs 2 and 3). Encouraged by these excellent works and connected with our ongoing efforts on $\mathrm{C}-\mathrm{O}$ bond cleavage, ${ }^{13}$ we herein wish to report iron-catalyzed allylic substitution of allylic ethers with Grignard reagents (eq 4).

$$
\text { (1) }
$$

We initially investigated the reactions of cinnamyl phenyl ether (1a) with phenyl magnesium bromide (2a) in the presence of iron catalyst to establish the reaction conditions (Table 1). $\mathrm{FeCl}_{2}$ and $\mathrm{Fe}(\mathrm{OAc})_{2}$ were completely inactive for the reaction (entries 1 and 2). The products of $\mathbf{3 a}$ and $\mathbf{4}$ were not observed and the allyl substrate 1a was fully recovered. A $20 \%$ yield of 3a was obtained in the presence of $\mathrm{FeCl}_{3}$ (entry 3). However, 1a was totally consumed and a Claisen rearrangement product was formed with $50 \%$ yield in this case. To our delight, the yield of 3a was improved to $47 \%$ and the allyl substrate 1a was remained in $55 \%$, indicating that the selectivity of the reaction is excellent by the use of $\mathrm{Fe}(\mathrm{acac})_{3}$ as catalyst (entry 4). Unfortunately, the yield of 3a was not increased by prolonging the reaction time due to the deactivation of the active catalyst species under the

* Corresponding author. Tel.: +86-10-6251-4226; fax: +86-10-6251-6444; e-mail: zhipingli@ruc.edu.cn 
reaction conditions (entry 5). When 1-methylpyrrolidin-2-one (NMP) was added as cosolvent, ${ }^{14}$ a $68 \%$ yield of 3 a was achieved (entry 6). Furthermore, the yield of 3a was improved to $99 \%$ by the increasing amount of NMP (entry 7). To our satisfactory, good to excellent yields of 3a were achieved by reducing of the catalyst loading (entries 8 and 9). However, the yield of 3a was reduced to $40 \%$ when 1.0 equivalent of 2a was applied (entry 10), due to the generation of biphenyl by the homocoupling of 2a. It should be noted that there is no reaction in the absence of iron catalyst (entry 11).

Table 1. Optimization of the reaction conditions ${ }^{a}$

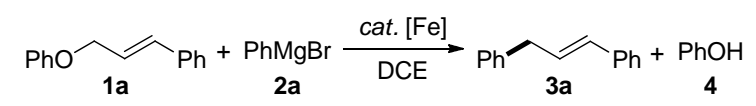

\begin{tabular}{|c|c|c|c|c|c|}
\hline entry & {$[\mathrm{Fe}](\mathrm{mol} \%)$} & additive & 3a $(\%)^{b}$ & $\mathbf{4}(\%)^{b}$ & $\begin{array}{l}\text { convn of 1a } \\
(\%)^{b}\end{array}$ \\
\hline 1 & $\mathrm{FeCl}_{2}(10)$ & - & 0 & 0 & 0 \\
\hline 2 & $\mathrm{Fe}(\mathrm{OAc})_{2}(10)$ & - & 0 & 0 & 0 \\
\hline 3 & $\mathrm{FeCl}_{3}(10)$ & - & 20 & 21 & 100 \\
\hline 4 & $\mathrm{Fe}(\mathrm{acac})_{3}(10)$ & - & 45 & 45 & 45 \\
\hline $5^{c}$ & $\mathrm{Fe}(\mathrm{acac})_{3}(10)$ & - & 45 & 45 & 45 \\
\hline 6 & $\mathrm{Fe}(\mathrm{acac})_{3}(10)$ & $\mathrm{NMP}^{d}$ & 68 & 62 & 73 \\
\hline 7 & $\mathrm{Fe}(\mathrm{acac})_{3}(10)$ & $\mathrm{NMP}^{e}$ & 99 & 96 & 100 \\
\hline 8 & $\mathrm{Fe}(\mathrm{acac})_{3}(2.5)$ & $\mathrm{NMP}^{e}$ & 99 & 96 & 100 \\
\hline 9 & $\mathrm{Fe}(\mathrm{acac})_{3}(1)$ & $\mathrm{NMP}^{e}$ & 81 & 80 & 82 \\
\hline $10^{f}$ & $\mathrm{Fe}(\mathrm{acac})_{3}(2.5)$ & $\mathrm{NMP}^{e}$ & 40 & 40 & 40 \\
\hline 11 & - & - & 0 & 0 & 0 \\
\hline
\end{tabular}

${ }^{a}$ Conditions: 1a $(0.5 \mathrm{mmol}), 2 \mathrm{a}(1.5 \mathrm{mmol}),[\mathrm{Fe}](5.0 \mathrm{~mol} \%)$, DCE $(5.0 \mathrm{~mL})$, $-15{ }^{\circ} \mathrm{C}, 1 \mathrm{~h}$, under $\mathrm{N}_{2}$, unless otherwise noted.

${ }^{b}$ Reported yields were based on 1a and determined by ${ }^{1} \mathrm{H}$ NMR using an internal standard.

${ }^{c} 3 \mathrm{~h}$.

${ }^{d} 2$ equiv.

${ }^{e} 9$ equiv.

fa $(0.5 \mathrm{mmol})$.

In order to investigate the influence of the leaving group, allylic substrates $\mathbf{1}$ with various leaving groups were examined under the optimized reaction conditions (Table 2). First, the derivatives of aryloxy allylic ethers $\mathbf{1 b}$ and $\mathbf{1 c}$ were subjected to react with $\mathbf{2 a}$ (entries 1 and 2 ). It was found that the electron-donating group on the phenyl ring showed better reactivity than the electron-withdrawing group performed. Second, other O-based leaving groups, such as methoxy 1d and acetate 1e, were not suitable for the transformation (entries 3 and 4). On the other hand, substrate 1f bearing bromo group was also not compatible for this iron-catalyzed allylic substitution reactions (entry 5), accompanied with $8 \%$ yield of the reduced product of $\mathbf{1 f}$, phenylpropene. ${ }^{15}$

Table 2. Screening of different leaving groups ${ }^{a}$

\begin{tabular}{|c|c|c|c|}
\hline $\mathrm{LG}^{\prime}$ & \multicolumn{2}{|c|}{ cat. $\mathrm{Fe}(\mathrm{acac})_{3}$} & $3 a \quad P h$ \\
\hline entry & 1 & 3a $(\%)^{b}$ & convn of $\mathbf{1}(\%)^{b}$ \\
\hline 1 & $\mathbf{1 b}, \mathrm{LG}=-\mathrm{OPh}-4-\mathrm{Me}$ & 99 & 100 \\
\hline 2 & 1c, $\mathrm{LG}=-\mathrm{OPh}-4-\mathrm{Br}$ & 67 & 72 \\
\hline 3 & 1d, $\mathrm{LG}=-\mathrm{OMe}$ & 37 & 37 \\
\hline
\end{tabular}

\begin{tabular}{|c|c|c|c|}
\hline 4 & $\mathbf{1 e}, \mathrm{LG}=-\mathrm{OAc}$ & 23 & 50 \\
\hline 5 & $\mathbf{1 f}, \mathrm{LG}=-\mathrm{Br}$ & 58 & 100 \\
\hline
\end{tabular}

${ }^{a}$ Conditions: $1(0.5 \mathrm{mmol}), 2 \mathrm{a}(1.5 \mathrm{mmol}), \mathrm{Fe}(\mathrm{acac})_{3}(2.5 \mathrm{~mol} \%)$, DCE $(5.0$ $\mathrm{mL}), \mathrm{NMP}(4.5 \mathrm{mmol}),-15{ }^{\circ} \mathrm{C}, 1 \mathrm{~h}$, under $\mathrm{N}_{2}$.

${ }^{b}$ Reported yields were based on $\mathbf{1}$ and determined by ${ }^{1} \mathrm{H}$ NMR using an internal standard.

Subsequently, we investigated the generality of ironcatalyzed allylic substitution of allylic ethers with Grignard reagents (Tables 3-4). The scope and limitation of Grignard reagents 2 were investigated by the use of 1a as a model substrate (Table 3 ). A variety of arylmagnesium bromides 2 bearing both electron-donating and electron-withdrawing substituents on the aromatic ring reacted smoothly with 1a to provide the desired products $\mathbf{3 b}$-e (entries 1-4). It is worth noting that many synthetically relevant functional groups such as chloro and fluoro were compatible with the conditions, revealing the possibility of further transformations by the well-established cross-coupling reactions. Although alkyl Grignard reagent 2f could be applied (entries 5), the efficiency of the reaction is lower than aromatic Grignard reagents. Notably, phenylmagnesium chloride $\mathbf{2 g}$ also reacted smoothly with 1a to give the desired product $3 \mathbf{a}$ in good yield (entry 6).

Table 3. Scope of Grignard reagents $2^{a, b}$

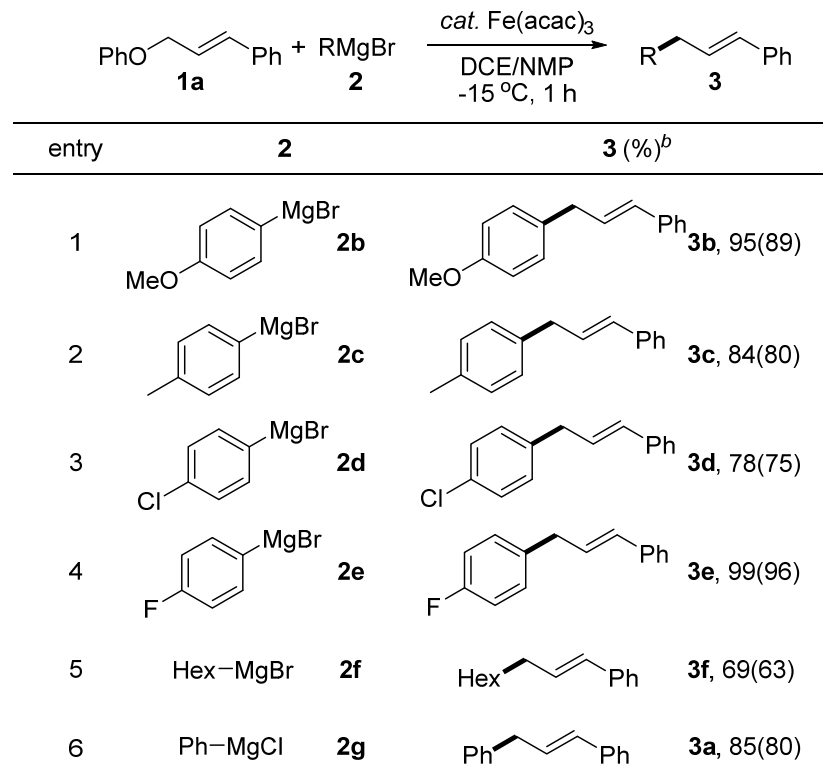

${ }^{a}$ Conditions: 1a $(0.5 \mathrm{mmol}), 2$ (1.5 mmol), Fe(acac) $)_{3}(2.5 \mathrm{~mol} \%)$, DCE (5.0 $\mathrm{mL}), \mathrm{NMP}(4.5 \mathrm{mmol}),-15{ }^{\circ} \mathrm{C}, 1 \mathrm{~h}$, under $\mathrm{N}_{2}$.

${ }^{b}$ Reported yields were based on 1a and determined by ${ }^{1} \mathrm{H}$ NMR using an internal standard; the yields were given in parentheses.

The scope of phenyl allylic ethers 1 was also examined (Table 4). 1 bearing the substituents on phenyl ring reacted efficiently with 2a (entries 1 and 2). 3-Phenoxybut-1-en-1yl)benzene 1i was also applicable, affording the desired product $3 \mathbf{i}$ in $75 \%$ yield (entry 3 ). Although the reactions of $\mathbf{1} \mathbf{j}$ and $1 \mathbf{k}$ with $2 \mathbf{a}$ were slow under the standard reaction conditions, good yields of $\mathbf{3} \mathbf{j}$ and $\mathbf{3 k}$ were achieved by prolonging the reaction time (entries 4 and 5). A mixture of linear and branch products $3 \mathbf{l}$ was generated by the reaction of 11 and 2a (entry 6). We hypothesized that a $\pi$-allyl iron intermediate was formed and the $\alpha$-selectivity of the reactions in the above examples was due to the steric effect. In contrast, 
the cyclic substrate $\mathbf{1 m}$ failed to undergo the allylic substitution, which suggested that the coordination of $\mathrm{C}=\mathrm{C}$ bond to iron might be required to cleave $\mathrm{C}-\mathrm{O}$ bond.

Table 4. Scope of allylic substrates $\mathbf{1}^{a, b}$

entry

${ }^{a}$ Conditions: 1 ( $\left.0.5 \mathrm{mmol}\right), 2 \mathrm{a}(1.5 \mathrm{mmol}), \mathrm{Fe}(\mathrm{acac})_{3}(2.5 \mathrm{~mol} \%)$, DCE (5.0 $\mathrm{mL}$ ), NMP $(4.5 \mathrm{mmol}),-15{ }^{\circ} \mathrm{C}, 1 \mathrm{~h}$, under $\mathrm{N}_{2}$, unless otherwise noted.

${ }^{b}$ Reported yields were based on $\mathbf{1}$ and determined by ${ }^{1} \mathrm{H}$ NMR using an internal standard; the yields were given in parentheses.

${ }^{c} 12 \mathrm{~h}$.

${ }^{d}$ Liner $:$ branch $=1.5: 1$.

In order to elucidate the possible reaction pathways, a isotope labeling experiment was carried out (Scheme 1). A mixture of $\gamma$-selective products $(5,6$ and 7) and $\alpha$-selective products (8 and $\mathbf{9})$ were obtained. The results indicated that $\sigma-$ $\pi$ - $\sigma$-equilibriums of iron catalyst and allyl substrates most likely exist in this type reaction.

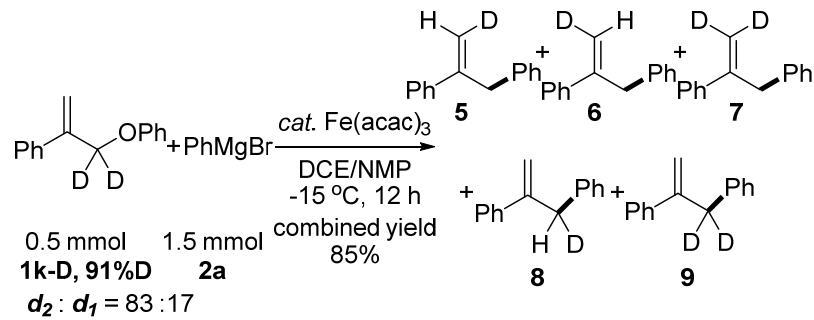

$5: 6: 7: 8: 9=8: 8: 57: 4: 23$

Scheme 1. Isotope labeling experiment.

Although the detailed mechanism for iron-catalyzed allylic substitution of allylic ethers with Grignard reagents is not yet clear at present, a tentative mechanism is depicted in Scheme 2. An active $\mathrm{Fe}(\mathrm{I})$ species is generated by the reduction of $\mathrm{Fe}(\mathrm{III}){ }^{7 \mathrm{a}, 9 \mathrm{a}, 16}$ Assisted by the coordination with alkene, intermediate $\mathbf{A}$ is formed by oxidative addition of $\mathrm{Fe}(\mathrm{I})$ to $\mathrm{C}$ $\mathrm{O}$ bond. .c, $8 \mathrm{~g}, 8 \mathrm{i}, 17$ Transmetallation followed by reductive elimination gives $\gamma$-selective product $\gamma$-3. The results in Scheme 1 might support this pathway, in which $\gamma$-selective products (5, 6 and 7) were obtained as major products. Meanwhile, the equilibriums of $\mathbf{A}, \mathbf{B}$, and $\mathbf{A}^{\prime}$ exist in the catalytic cycle. Accordingly, $\alpha$-selective product $\alpha-3$ can be delivered, depending on the steric effect of the substituents $\mathrm{R}^{1}$ and $\mathrm{R}^{3}$. However, other possible reaction pathways including $\mathrm{S}_{\mathrm{N}} 2$ ' and $\mathrm{S}_{\mathrm{N}} 2$ could not be excluded at this moment. ${ }^{18}$

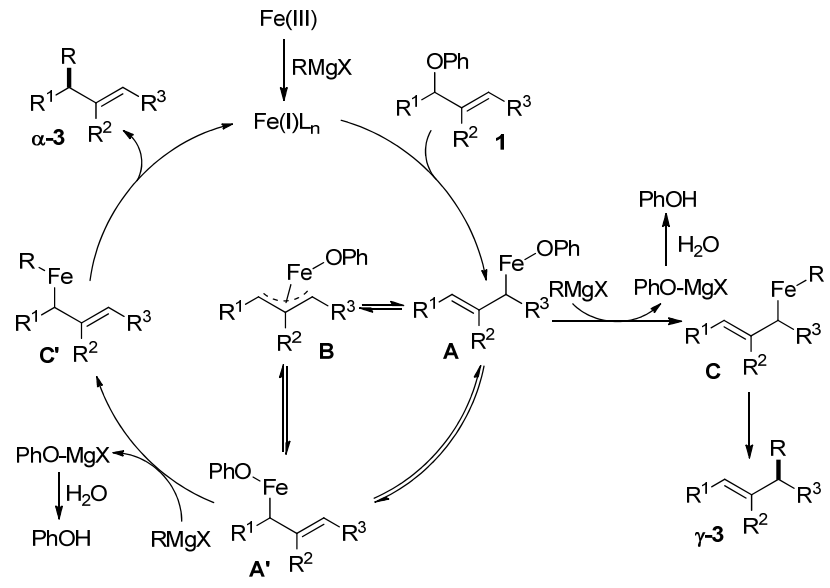

Scheme 2. A proposed mechanism.

In conclusion, the first Fe-catalyzed allylic substitution of phenyl allylic ethers with Grignard reagents has been realized by the use of phenoxy group as a leaving group. The coupling products were presumably generated through $\sigma-\pi-\sigma$-equilibriums of iron catalyst and allyl substrates.

Acknowledgment. Financial support from the National Science Foundation of China (21272267), State Key Laboratory of Heavy Oil Processing (SKLOP201401001), and Beijing National Laboratory for Molecular Sciences (BNLMS).

Supporting information available: Experimental procedures, spectrum data, and NMR spectra of the compounds. This material is available free of charge via the Internet at

\section{References and notes}

1. (a) Weaver, J. D.; Recio III, A.; Grenning, A. J.; Tunge, J. A. Chem. Rev. 2011, 111, 1846; (b) Lu, Z.; Ma, S. Angew. Chem., Int. Ed. 2008, 47, 258; (c) Yorimitsu, H.; Oshima, K. Angew. Chem., Int. Ed. 2005, 44, 4435; (d) Trost, B. M.; Crawley, M. L. Chem. Rev. 2003, 103, 2921; (e) Trost, B. M.; Van Vranken, D. L. Chem. Rev. 1996, 96, 395.

2. (a) Butt, N. A.; Zhang, W. Chem. Soc. Rev. 2015, 44, 7929; (b) Sundararaju, B.; Achard, M.; Bruneau, C. Chem. Soc. Rev. 2012 41, 4467; (c) Bandini, M. Angew. Chem., Int. Ed. 2011, 50, 994; (d) Harutyunyan, S. R.; Hartog, T. d.; Geurts, K.; Minnaard, A. J.; Feringa, B. L. Chem. Rev. 2008, 108, 2824; (e) Tamaru, Y. Eur. J. Org. Chem. 2005, 2647; (f) Muzart, J. Tetrahedron 2005, 61, 4179.

3. Cu-catalyzed allylic ether substitutions with organometallic reagents: (a) Pérez, M.; Fañanás-Mastral, M.; Hornillos, V.; Rudolph, A.; Bos, P. H.; Harutyunyan, S. R.; Feringa, B. L. Chem. Eur. J. 2012, 18, 11880; (b) Park, J. K.; Lackey, H. H.; Ondrusek, B. A.; McQuade, D. T. J. Am. Chem. Soc. 2011, 133, 2410; (c) Lauer, A. M.; Mahmud, F.; Wu, J. J. Am. Chem. Soc. 2011, 133, 9119; (d) Bertozzi, F.; Pineschi, M.; Macchia, F.; Arnold, L. A.; Minnaard, A. J.; Feringa, B. L. Org. Lett. 2002, 4, 2703.

4. Ni-catalyzed allylic ether substitutions with organometallic reagents: (d) Tao, J.-L.; Yang, B.; Wang, Z.-X. J. Org. Chem. 2015, 80, 12627; (b) Chung, K.-G.; Miyake, Y.; Uemura, S. J. Chem. Soc., Perkin Trans. 2000, 1, 2725; (c) Didiuk, M. T.; Morken, J. P.; Hoveyda, A. H. Tetrahedron 1998, 54, 1117; (d) Didiuk, M. T.; Morken, J. P.; Hoveyda, A. H. J. Am. Chem. Soc. 1995, 117, 7273

5. Pd-catalyzed allylic ether substitutions with organometallic reagents: (a) Moser, R.; Nishikata, T.; Lipshutz, B. H. Org. Lett. 
2010, 12, 28; (b) Nishikata, T.; Lipshutz, B. H. J. Am. Chem. Soc. 2009, 131, 12103.

6. Other metal-catalyzed allylic ether substitutions with organometallic reagents: (a) Suzuki, N.; Kondakov, D. Y.;

Takahashi, T. J. Am. Chem. Soc. 1993, 115, 8485; (b) Lalic, G.; Blum, S. A.; Bergman R. G. J. Am. Chem. Soc. 2005, 127, 16790; (c) Lysenko, I. L.; Kim, K.; Lee, H. G.; Cha, J. K. J. Am. Chem. Soc. 2008, 130, 15997; (d) Kiuchi, H.; Takahashi, D.; Funaki, K.; Sato, T.; Oi, S. Org. Lett. 2012, 14, 4502; (e) Evans, P. A.; Oliver, S. Org. Lett. 2013, 15, 5626; (f) Yasui, H.; Mizutani, K.;

Yorimitsu, H.; Oshima, K. Tetrahedron 2006, 62, 1410.

7. (a) Bauer, I.; Knölker, H.-J. Chem. Rev. 2015, 115, 3170; (b) Jia, F.; Li, Z. Org. Chem. Front. 2014, 1, 194; (c) Sun, C.-L.; Li, B.-J.; Shi, Z.-J. Chem. Rev. 2011, 111, 1293; (d) Correa, A.; Mancheño, O. G.; Bolm, C. Chem. Soc. Rev. 2008, 37, 1108. (e) Bolm, C.; Legros, J.; Paih, J. L.; Zani, L. Chem. Rev. 2004, 104, 6217.

8. (a) Lindermayr, K.; Plietker, B. Angew. Chem., Int. Ed. 2013, 52, 12183; (b) Dieskau, A. P.; Holzwarth, M. S.; Plietker, B. Chem. Eur. J. 2012, 18, 2423; (c) Yu, C.; Zhou, A.; He, J. RSC Adv. 2012, 2, 8627; (d) Dieskau, A. P.; Plietker, B. Org. Lett. 2011, 13, 5544; (e) Holzwarth, M. S.; Frey, W.; Plietker, B. Chem. Commun. 2011, 47, 11113; (f) Jegelka, M.; Plietker, B. Chem. Eur. J. 2011, 17, 10417; (g) Jegelka, M.; Plietker, B. Org. Lett. 2009, 11, 3462; (h) Holzwarth, M.; Dieskau, A.; Tabassam, M.; Plietker, B. Angew. Chem., Int. Ed. 2009, 48, 7251; (i) Plietker, B.; Dieskau, A.; Möws, K.; Jatsch, A. Angew. Chem., Int. Ed. 2008, 47, 198; (j) Zhou, B.; Xu, Y. J. Org. Chem. 1988, 53, 4419; (k) Xu, Y.; Zhou, B. J. Org. Chem. 1987, 52, 974.

9. $\mathrm{X}(\mathrm{Br}, \mathrm{Cl})$ as a leaving group: (a) Fürstner, A.; Martin, R.; Krause, H.; Seidel, G.; Goddard, R.; Lehmann, C. W. J. Am. Chem. Soc. 2008, 130, 8773; Sulfonyl chlorides as a leaving group: (b) Volla C. M. R.; Marković, D.; Dubbaka, S. R.; Vogel, P. Eur. J. Org. Chem. 2009, 6281; OMe as a leaving group: (c) Xie, X.; Fox, J. M. Synthesis 2013, 45, 1807; OAc as a leaving group: (d) Mayer, M.; Czaplik, W. M.; von Wangelin, A. J. Adv. Synth. Catal. 2010, 352, 2147.

10. Yanagisawa, A.; Nomura, N.; Yamamoto, H. Tetrahedron 1994, $50,6017$.

11. Nakamura, M.; Matsuo, K.; Inoue, T.; Nakamura, E. Org. Lett. 2003, 5, 1373 .

12. Hata, T.; Bannai, R.; Otsuki, M.; Urabe, H. Org. Lett. 2010, 12, 1012.

13. Reviews on C-O bond cleavage: (a) Su, B.; Cao, Z.-C.; Shi, Z.-J. Acc. Chem. Res. 2015, 48, 886; (b) Cornella, J.; Zarate, C.; Martin, R.; Chem. Soc. Rev. 2014, 43, 8081; (c) Li, W.-N.; Wang, Z.-L. RSC Adv. 2013, 3, 25565; (d) Li, B.-J.; Yu, D.-G.; Sun, C.L.; Shi, Z.-J. Chem. Eur. J. 2011, 17, 1728; (e) Yu, D.-G.; Li, B.J.; Shi, Z.-J. Acc. Chem. Res. 2010, 43, 1486.

14. (a) Kleimark, J.; Hedström, A.; Larsson, P.-F.; Johansson, C.; Norrby, P.-O. ChemCatChem 2009, 1, 152; (b) Cahiez, G.; Avedissian, H. Synthesis 1998, 1199.

15. An allylic radical intermediate was mostly generated through bromo-abstraction by iron catalyst, see: (a) Jin, M; Adak, L.; Nakamura, M. J. Am. Chem. Soc. 2015, 137, 7128; (b) Noda, D.; Sunada, Y.; Hatakeyama, T.; Nakamura, M.; Nagashima, H. J. Am. Chem. Soc. 2009, 131, 6078.

16. (a) Lefèvre, G.; Jutand, A. Chem. Eur. J. 2014, 20, 4796; (b) Schoch, R.; Desens, W.; Werner, T.; Bauer, M. Chem. Eur. J. 2013, 19, 15816; (c) Kleimark, J.; Larsson, P.-F.; Emamy, P.; Hedström, A.; Norrby, P.-O. Adv. Synth. Catal. 2012, 354, 448; (d) Hedström, A.; Bollmann, U.; Bravidor, J.; Norrby, P.-O. Chem. Eur. J. 2011, 17, 11991; (e) Tamao, K.; Sumitani, K.; Kumada, M. J. Am. Chem. Soc. 1972, 94, 4374.

17. Nishikata, T.; Lipshutz, B. H. J. Am. Chem. Soc. 2009, 131, 12103.

18. Kar, A.; Argade, N. P. Synthesis 2005, 18, 2995. 


\section{Graphical Abstract}

To create your abstract, type over the instructions in the template box below.

Fonts or abstract dimensions should not be changed or altered.

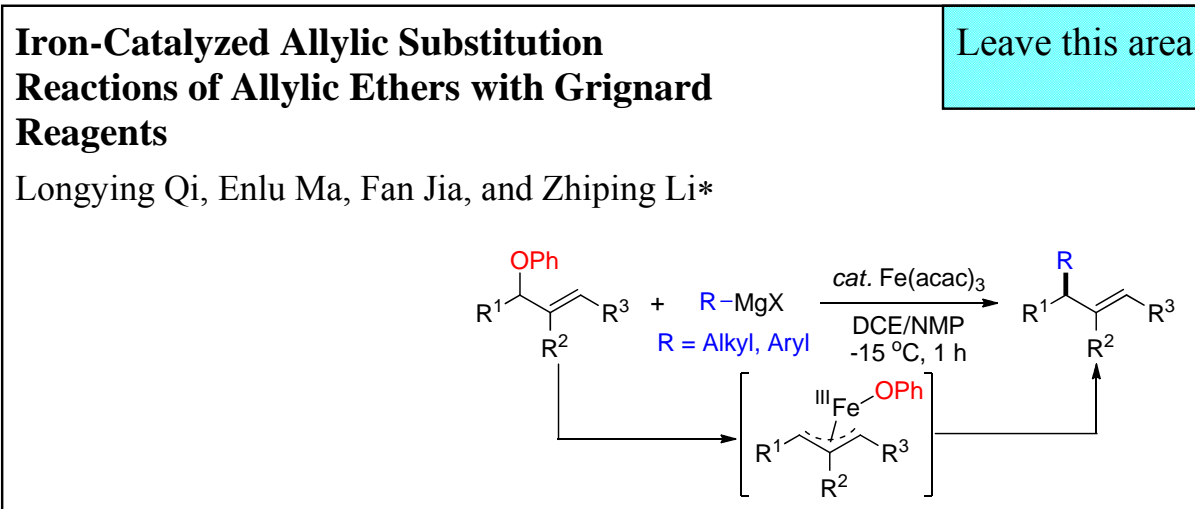

